EGU2020-20255

https://doi.org/10.5194/egusphere-egu2020-20255

EGU General Assembly 2020

(c) Author(s) 2021. This work is distributed under

the Creative Commons Attribution 4.0 License.

\title{
Global network of underground research - Literature metadata analysis by Geographic Information Systems (GIS)
}

\author{
Ossi Kotavaara ${ }^{1}$, Jari Joutsenvaara ${ }^{1}$, Eija-Riitta Niinikoski ${ }^{1}$, Pertti Martinmäki ${ }^{2}$, and Ursula \\ Heinikoski ${ }^{2}$ \\ ${ }^{1}$ University of Oulu, Kerttu Saalasti Institute, Regional Excellence, Oulu, Finland (ossi.kotavaara@oulu.fi) \\ ${ }^{2}$ University of Oulu, Oulu University Library, Oulu, Finland (pertti.martinmaki@oulu.fi)
}

Globally there are various underground facilities or laboratories, which are commonly located in active or closed mines, in tunnel systems or they are built for this specific purpose. There are also a vast number of study groups and researches within several disciplines utilising resources of these facilities. The Baltic Sea Underground Innovation Network (BSUIN) develops six such facilities, all having unique characteristics and operational settings. In developing underground laboratories, understanding characteristics, needs and accessibility of research communities applying these facilities is crucial. Aim of this study is to product new knowledge in this field, by analysing research published by this community. Geographic information systems (GIS) is applied to scrutinise the metadata of scientific literature databases. There is a great deal of published research having connection to underground facilities. For example, between years 2009-2018, Scopus database covers over 13,000 articles by over 40,000 authors. Preliminary analysis indicates that a wide variety of disciplines, such as engineering, earth and planet sciences, environmental sciences, physics and astronomy, as well as energy, material, computer and social sciences, are active within underground themes. In the analysis, publication specific data are compiled from literature databases, research units located globally by geocoding and data is organised for geographic and temporal analysis. By discipline information and indexed research fields and themes, patterns of global research trends within underground studies are explored. Results will indicate how distribution of study fields is organised, visualise the strength and activity of different disciplines and show the key temporal elements in development of research. This data enables also to extend the analysis to cover also the networked characteristics of research and researchers within underground laboratories. 